\title{
OCULAR PROBLEMS IN CEREBRAL PALSY
}

\author{
Rajesh R. Nayak1, Usha Bhanu Kommineni²
}

${ }^{1}$ Associate Professor, Department of Ophthalmology, Kasturba Medical College, Mangalore.

2Postgraduate Student, Department of Ophthalmology, Kasturba Medical College, Mangalore.

\section{ABSTRACT}

\section{BACKGROUND}

A high incidence of ocular defects is noted in children diagnosed with cerebral palsy. Untreated defects have a bearing on the child's education, hence it is important to identify and treat at the earliest.

\section{MATERIALS AND METHODS}

Children affected with cerebral palsy referred from the high-risk clinic of our hospital were studied for ocular defects.

\section{RESULTS}

Of the 75 children examined, 25 (33.33\%) had normal eyes and ocular adnexa. Refractive error was seen in $48 \%$ of the cases. There incidence of squint was $26.67 \%$. Nystagmus was seen in $16 \%$ of the cases and fundus abnormalities was seen in $16 \%$ of cases. Early identification of treatable ocular defects and their treatment along conventional lines was done.

\section{CONCLUSION}

A full ophthalmological assessment should be a part of the routine assessment of the children diagnosed with cerebral palsy and efforts should be made that their visual function is at its best.

\section{KEYWORDS}

Cerebral Palsy, Refractive Errors, Squint, Nystagmus, VEP.

HOW TO CITE THIS ARTICLE: Nayak RR, Kommineni UB. Ocular problems in cerebral palsy. J. Evolution Med. Dent. Sci. 2017;6(4):286-289, DOI: 10.14260/Jemds/2017/65

\section{BACKGROUND}

Cerebral palsy is a static encephalopathy that may be defined as a non-progressive disorder of posture and movements often associated with epilepsy and abnormalities of speech, vision and intellect resulting from defect or lesion of the developing brain.(1)

Cerebral palsy comprises of a group of condition of different aetiologies, but with distinctive clinical features. The motor abnormalities dominate the clinical features and form the basis for the definition of cerebral palsy. It is customary to classify cerebral palsy based on type of motor abnormality and its topography. Thus majority of motor disorders are spastic, athetoid or atonic and the topography relates to the description of limb or limbs involved.(1)(2) While motor abnormalities are most significant clinically, these are commonly associated with varying degree of mental abnormalities, emotional instability and convulsive disorders. Additionally, sensory abnormalities, particularly deafness and visual disability are common and yet the later still does not seem to merit the attention that it deserves.

Early identification of ocular problems in children with cerebral palsy and early management whenever possible will go a long way in helping accelerating the development of the child and acquisition of new skills and also minimises visual handicap in these mentally retarded children.

Financial or Other, Competing Interest: None.

Submission 06-12-2016, Peer Review 30-12-2016,

Acceptance 06-01-2017, Published 12-01-2017.

Corresponding Author:

Dr. Rajesh R. Nayak,

Associate Professor

Department of Ophthalmology

Kasturba Medical College

Attavar, Mangalore-575001,

Karnataka, India.

E-mail: eyenayak@yahoo.com

DOI: $10.14260 /$ jemds $/ 2017 / 65$

In this study, we aim to diagnose different types of ocular problems in cerebral palsy which included analysis of refractive error, squint and ocular motility problems and fundus abnormality. Also, co-relation between optic disc pallor and VEP study was studied and early management to accelerate visual rehabilitation.

\section{MATERIALS AND METHODS}

We took 75 cases of cerebral palsy, which were referred to us by the high-risk clinic of the Department of Paediatrics of our hospital. This study was done between September 2013 and December 2014. The history was recorded from the mother supported by her husband or near relatives. A pertinent antenatal, natal and neonatal history was taken. The age group was between 3 months and 15 years. They were examined for the presence of refractive errors, strabismus and nystagmus. Fundus abnormalities were also looked for. Vision was assessed in the following manner.

a) Children with better IQ object screen on the Snellen's chart was used.

b) In very young children and children with low IQ, vision was assessed depending on the fixation pattern as below in Table 1.

\begin{tabular}{|c|c|}
\hline Fixation & Visual Acuity \\
\hline Central and steady maintenance of fixation & $6 / 6$ to $6 / 9$ \\
\hline $\begin{array}{c}\text { Central and steady without maintenance of } \\
\text { fixation }\end{array}$ & $6 / 12$ to $6 / 18$ \\
\hline Central but unsteady fixation & $6 / 24$ to $6 / 36$ \\
\hline Eccentric fixation & $6 / 60$ \\
\hline Wandering or poor fixation & Poor vision \\
\hline \multicolumn{2}{|c|}{ Table 1. Assessment of Vision in Low IQ Children } \\
\hline
\end{tabular}

In the children with poor fixation, VEP study was done. Squint was assessed with the help of Hirschberg test and with the help of prism bar. All the children were dilated with 
atropine ointment $1 \%$ twice daily for 3 days or cyclopentolate $0.5 \%$ eye drops for retinoscopy and dilated fundus.

\section{RESULTS}

This observational study was done in 75 cases between September 2014 and December 2015. In this study, 31 (41.33\%) children belonged to 0 - 2 years' age group which constituted the highest, 26 (34.67\%) children between $3-5$ years' group, 18 (24\%) children were above 5 years. Out of 75 children 46 were male and 29 were female.

Natal causes constituted (52\%) the major aetiological factor responsible for cerebral palsy. The aetiology was unknown in $14.67 \%$ of cases, which formed the second large proportion. Table 2 below shows the various aetiological factors of cerebral palsy.

\begin{tabular}{|c|c|c|}
\hline Aetiological Factor & Number of Children & \% \\
\hline Prenatal - & 6 & \\
Genetic & 3 & 8 \\
Consanguinity & 2 & \\
Intrauterine Infection & 1 & \\
\hline Natal - & 39 & 52 \\
Anoxia & 17 & \\
Prematurity & 17 & \\
Prolonged labour & 2 & 13.33 \\
IUGR & 3 & \\
\hline Postnatal- & 10 & 12 \\
Meningitis & 2 & 14.67 \\
Encephalitis & 4 & \\
Convulsions & 3 & \\
Neonatal jaundice & 9 & 11 \\
\hline Mixed & $\mathbf{7 5}$ & \\
\hline Unknown & & \\
\hline Total & Table 2. Aetiologyof Cerebral Palsy & \\
\hline
\end{tabular}

In this study, $93.33 \%$ of children presented with spastic type of cerebral palsy with 35 of them having quadriplegia, 26 with diplegia, 8 with hemiplegia and 1 with double hemiplegia; 3 cases (4\%) presented with atonic cerebral palsy and 2 cases $(2.66 \%)$ had athetoid cerebral palsy.
In this study 50 eyes showed vision of $6 / 6$ to $6 / 9,48$ eyes showed vision of $6 / 12$ to $6 / 18,24$ eyes showed vision of $6 / 24$ to $6 / 36,6$ eyes showed vision of $6 / 60$, while poor vision of $<6 / 60$ was recorded in 28 eyes; 36 children which constitute $48 \%$ of our study had refractive errors as shown in Table 3.

\begin{tabular}{|c|c|c|c|c|c|c|}
\hline $\begin{array}{c}\text { Type of Refractive } \\
\text { Error }\end{array}$ & $\begin{array}{c}\text { Spastic } \\
\text { Quadriplegia }\end{array}$ & $\begin{array}{c}\text { Spastic } \\
\text { Diplegia }\end{array}$ & $\begin{array}{c}\text { Spastic } \\
\text { Hemiplegia }\end{array}$ & $\begin{array}{c}\text { Double } \\
\text { Hemiplegia }\end{array}$ & Atonic & Athetoid \\
\hline Hypermetropia & 9 & 4 & 2 & 0 & 0 & 0 \\
\hline Myopia & 2 & 5 & 1 & 1 & 0 & 0 \\
\hline Astigmatism-Myopia & 1 & 3 & 0 & 0 & 2 & 0 \\
\hline Astigmatism-Hypermetropia & 4 & 2 & 0 & 0 & 0 & 0 \\
\hline Total (36) & $\mathbf{1 6}$ & $\mathbf{1 4}$ & $\mathbf{3}$ & $\mathbf{1}$ & $\mathbf{2}$ & $\mathbf{0}$ \\
\hline \multicolumn{6}{|l}{ Table 3. Refractive Errors in Various Types of Cerebral Palsy } \\
\end{tabular}

In our study, hypermetropia of more than $+2 \mathrm{D}$ was seen in $16 \%$ (12 children) of the cases and myopia of less than - 6D was seen in $12 \%$ ( 9 children) of cases; 18 pairs of spectacles were prescribed and there was good acceptance of these spectacles by these children.

In our study, we found out that hypermetropia and hypermetropic astigmatism was more common in spastic quadriplegia and myopia and myopic astigmatism in spastic diplegia.

The incidence of squint in our study was $26.67 \%$ (20/75), out of which only 2 cases $(2.67 \%)$ had paralytic squint and 18 cases (24\%) had non-paralytic squint. Ratio of convergent to divergent squint among concomitant squints was 2:1 (12 cases of convergent: 6 cases of divergent). Six cases of convergent squint were accommodative in nature and rest were non-accommodative. Four of the concomitant squint had obvious abnormalities of the disc.

\begin{tabular}{|c|c|c|c|}
\hline Type of CP & $\begin{array}{c}\text { Total No. } \\
\text { of Cases }\end{array}$ & $\begin{array}{c}\text { No. of Cases } \\
\text { with Squint }\end{array}$ & Percentage \\
\hline $\begin{array}{c}\text { Spastic } \\
\text { quadriplegia }\end{array}$ & 35 & 8 & $22.85 \%$ \\
\hline Spastic diplegia & 26 & 7 & $26.90 \%$ \\
\hline $\begin{array}{c}\text { Spastic } \\
\text { hemiplegia }\end{array}$ & 8 & 4 & $50 \%$ \\
\hline $\begin{array}{c}\text { Double } \\
\text { hemiplegia }\end{array}$ & 1 & 0 & 0 \\
\hline Atonic & 3 & 1 & $33.33 \%$ \\
\hline Athetoid & 2 & 0 & 0 \\
\hline \multicolumn{4}{|c|}{ Table 4. Number of Squint Cases in Each } \\
Type of Cerebral Palsy \\
\hline
\end{tabular}

14 cases of amblyopia were detected in this study of which 9 cases were detected to have strabismic amblyopia, 4 cases had anisometropic amblyopia and 1 case had amblyopia ex anopsia. Three cases of strabismic amblyopia showed improvement with occlusion therapy. 
In the present study, there were 12 cases with nystagmus (16\%). Nystagmus was found in only ataxic and spastic types of cerebral palsy. Five cases had searching or pendular nystagmus associated with obvious ocular lesions. Three children had pure latent nystagmus associated in each case with convergent squint. Rest of four cases had horizontal nystagmus.

Fundus examination was done in all cases; 16\% (12/75) of the cases had positive findings on fundus examination. Pale disc was seen in seven cases, pigmentary retinal changes with tapetal reflex in two, Leber's amaurosis in one, persistent hyperplastic posterior primary vitreous in one and one case had morning glory syndrome.

Fundus abnormalities were noted in five cases (14.28\%) of spastic quadriplegia, three cases $(11.53 \%)$ of spastic diplegia, 1 case $(12.5 \%)$ of spastic hemiplegia, 2 cases (66.67\%) of atonic cerebral palsy and 1 case $(50 \%)$ of athetoid cerebral palsy.

VEP was done in cases with poor fixation and who had a suspicious optic disc. A total number of 15 cases were taken for VEP, which included 7 cases of pale disc. VEP was absent in 6 cases and latency was seen in 1 case. Out of 8 cases who had normal VEP recording, 3 cases had pale disc.

\section{DISCUSSION}

Ocular abnormalities are very common in children with cerebral palsy. Spastic children are more likely to have ocular defects than athetoid and ataxic children. The pathology in spastic is more extensive and diffuse with periventricular haemorrhage, sub-cortical haemorrhage and cortical atrophy. In athetoid children it is centered on, although not confined to the basal ganglia and in ataxic children on the cerebellum. According to several studies, refractive errors and squint form the largest group of abnormalities in cerebral palsy.(3)

In this study, there was a preponderance of cases under 5 years of age probably reflecting a lack of periodic evaluation and appropriate intervention. A male preponderance was observed with the male-to-female ratio being 1.59:1. This observation is similar to a study conducted by Srivastava et al, which showed a male-to-female ratio of 1.86:1.(4)

Natal causes like anoxia, prematurity constitute the major aetiological factor responsible for cerebral palsy in our study which is in accordance with a study conducted by Srivastava et al.(4) Also maximum children presented with spastic type (93.33\%) of cerebral palsy with higher number of spastic quadriplegia cases.

The incidence of ocular pathology in our study correlates with the study conducted by Sabita et al, where $68 \%$ of cerebral palsy children were affected, while in our study $66.67 \%$ showed ocular involvement.(2)

Many authors have not mentioned about visual acuity assessment, because of difficulty in recording vision in these children with low IQ and poor co-operation.

36 children which constitute $48 \%$ of our study had refractive errors, which is significantly higher compared to a normal study group of typically developing children.(3)

Hypermetropia of more than $+2 \mathrm{D}$ was seen in $16 \%$ of the cases, which is more than the incidence in the study conducted by Sabita et al, which was $4 \%$. Also in our study myopia of less than - 6D was seen in $12 \%$ of cases which was similar to the study conducted by Sabita et al, which was $11.5 \% .{ }^{(2)}$
In our study, we found out that hypermetropia and hypermetropic astigmatism was more common in spastic quadriplegia and myopia and myopic astigmatism in spastic diplegia.

Incidence of refractive errors in spastic quadriplegia, diplegia and hemiplegia is comparable with incidence of refractive errors in a study conducted by Peter Black.(5)

In the dystonic cerebral palsies, hypermetropia predominates. This has been explained as a failure of maturation of the visual system related to neonatal hypoxia. It does seem clear that the normal changes with age that occur in hypermetropia do not occur in cerebral palsied children. However, for this study to happen it has been stated that the injury has to occur during the perinatal period, otherwise the incidence of refractive error approaches that of a normal population. In the admittedly small number of children in this series who acquired their cerebral palsy at least 21 days after birth, $50 \%$ had refractive errors and this is contrary to previous findings.

There were four cases of anisometropic amblyopia in this study. However, this may be more because the visual acuity assessment of these children is quite unreliable because of low IQ. The treatment of amblyopia is also important and the identification at an early age of defects likely to lead to it. The very nature of the child's underlying disability will render him or her accident prone, particularly when the shelter of school is left behind. Although, no figures can be found, it must remain a possibility. Every effort should be made where possible to ensure that both eyes have useful vision.

Ratio of convergent to divergent squint among concomitant squints was 2:1 (12 cases of convergent: 6 cases of divergent). This ratio is usually 8 - 10: 1 in normal squinting population. It is quite evident from the figures that incidence of squint is more in cerebral palsy children when compared to normal and also the incidence of convergent squint among the concomitant squint was high when compared to normal squinting population. Incidence of squint was high in spastic diplegia and quadriplegia, which is comparable with the high incidence in the group in the study by Peter Black.(5) This is probably due to more number of children in this group.

Many authors have considered the treatment of squint unrewarding, because of the low rate of success as assessed along conventional lines and the high incidence of consecutive squint following surgery, due in part at least to central obstacles to fusion. But it seems reasonable that every attempt should be made to treat squint as if the child was otherwise normal. Even the purely cosmetic aspects assume importance, both for parent and patient, though surgery has to be balanced against submitting a child to yet another surgical procedure.

Nystagmus was seen in $16 \%$ of the cases, incidence of which was less than the incidence in a study conducted by Sabita et al and was found only in spastic and ataxic cases. (2)

Pale disc was the commonly noted positive finding on fundus examination in our study. It is comparable to Sabita et al study. In this study, a few cases with pale disc had a normal VEP recording. This indicated that their optic nerve function was good in spite of presence of temporal pallor of the disc. This shows that the temporal pallor cannot be the criteria for assessing the visual function. 
Fields were not done in the present study, because the age of children in our study group was less than 5 years in most of the cases. However, field defects do not seem to have merited the attention they deserve.

High incidence of ocular defects found in children with cerebral palsy is comparable with other workers findings, probably a reflection of severity of cerebral palsy. Evidences suggest that degree of ocular abnormality increases with degree of mental subnormality.

\section{CONCLUSION}

Visual disabilities in children with cerebral palsy are common. Errors of refraction, squint, amblyopia and fundus abnormalities are seen in a high percentage of these children. These constitute to a significant amount of visual handicap, which is attributed solely due to cortical causes. It is treatment of these visual defects, which is important to enable rehabilitation. It is important to identify and treat these defects along conventional lines whenever possible. The education of these children relies heavily on visual stimulation, particularly those with sensory deafness. The teachers particularly need to know the visual handicaps of these children. Children with multiple handicaps require as much help as possible, and this should include thorough ophthalmological assessment and care. The diagnosis of cerebral palsy is usually made at a time when such a child reaches 12 months of age and rarely after 18 months. Hence, it is quite essential that all children with cerebral palsy should undergo detailed ophthalmic examination to minimize visual handicaps in these children and help these children for early visual rehabilitation.

\section{REFERENCES}

[1] O'Shea TM. Diagnosis, treatment, and prevention of cerebral palsy. Clin Obstet Gynecol 2008;51(4):816-28.

[2] Katoch S, Devi A, Kulkarni P. Ocular defects in cerebral palsy. Indian J Ophthalmol 2007;55(2):154-6.

[3] Saunders KJ, Little JA, Mcclelland JF, et al. Profile of refractive errors in cerebral palsy: impact of severity of motor impairment (GMFCS) and CP subtype on refractive outcome. Invest Ophthalmol Vis Sci 2010;51(6):2885-90.

[4] Srivastava VK, Laisram N, Srivastava RK. Cerebral plasy. Indian Paediatr 1992;29(8):993-6.

[5] Black P. Visual disorders associated with cerebral palsy. Br J Ophthalmol 1982;66(1):46-52. 